\title{
A HISTÓRIA DAS POLÍTICAS EDUCACIONAIS NO MUNICÍPIO DE SÃO PAULO: UM SOBREVOO ENTRE OS ANOS 1983 E 2007
}

\author{
A. B. F. ISHII \\ Pontifícia Universidade Católica de São Paulo - PUC/SP \\ ab.ishii@uol.com.br
}

Artigo submetido em julho/2015 e aceito em dezembro/2015

DOI: $10.15628 /$ holos.2015.3247

\section{RESUMO}

Este artigo faz parte da minha pesquisa de doutoramento e trata-se de um breve sobrevoo pelas implementações de políticas públicas para a Educação. Tem o intuito de situar, no tempo, a rede municipal da cidade de São Paulo, bem como de investigar como se deu a organização e o desenvolvimento curricular nas gestões de acordo com os regimes no poder - uma vez que se consideram as políticas curriculares vigentes resultado também de políticas anteriores. Neste artigo, objetiva-se resgatar o significado das alternâncias de poder público para a Educação desde a gestão de Mario Covas, na Prefeitura da cidade de São Paulo, até o final da gestão do Prefeito Gilberto Kassab. Ressalta o contexto histórico de lutas que reflete não apenas empreendimentos políticos, mas também as lutas e os esforços da sociedade civil por seus direitos. Evidenciou-se nesse estudo uma grande oscilação partidária e ideológica da chefia do poder executivo, alterando também proposições e diretrizes curriculares para as escolas da rede municipal da cidade de São Paulo. Nessa breve revisita, evidenciamse as principais medidas realizadas na área curricular até a elaboração de orientações curriculares para a primeira etapa do ensino fundamental implementadas na rede no ano de 2007.

PALAVRAS-CHAVE: Políticas Públicas de Educação, movimentos sociais, implementações curriculares.

\section{HISTORY OF EDUCATIONAL POLICIES IN THE MUNICIPALITY OF SÃO PAULO: A GLANCE OVER THE YERS 1983-2007}

\begin{abstract}
The present article is part of my PhD research and this is a brief scan on public policy implementations for Education. It intends to position chronologically the municipal public system in São Paulo, as well as to investigate how the organization and curriculum development efforts came about regarding the established governments, since current curriculum policies are likewise considered as a result of previous policies. In this article, the objective is to resume the meaning of government alternations for Education from the beginning of Mario Covas' to the end of Gilberto
\end{abstract}

Kassab's managements, both former mayors of São Paulo. This article points out the historical context of struggles that reflects not only political projects, but also the efforts of civil society for their rights. This research evinced a large partisan and ideological oscillation of the leadership of the executive power, which is also changing curricular propositions and directives for municipal schools in São Paulo. This concise review shows the principal actions took in the curricular area up to the development of curricular guidelines for primary school implemented for municipal schools in 2007.

KEYWORDS: Public Policies of Education, social movements, curriculum implementations. 


\section{INTRODUÇÃO}

São Paulo, a maior cidade do Brasil, tem $1.443 \mathrm{~km}^{2}$. Vivem nela mais de 10 milhões de habitantes pertencentes a diversos segmentos populacionais, o que caracteriza uma grande heterogeneidade. Os habitantes da cidade convivem com uma complexidade de padrões socioeconômicos dos países mais pobres do planeta até aos dos mais ricos.

Essa metrópole destaca-se no cenário nacional pela força da sua economia e geração de riquezas. As decisões políticas ocorridas em São Paulo repercutem, não raro, em outros locais, devido à grande circulação de capital em fluxo na cidade.

Além dos aspectos socioeconômicos, a gestão política do município caracteriza-se por uma grande oscilação partidária entre "progressistas" e "conservadores". A chefia do executivo municipal alternou-se ideologicamente de 1983 a 2007: Mário Covas (Movimento Democrático Brasileiro)-11/05/1983 a 01/01/1986, Jânio Quadros (Partido Trabalhista Brasileiro) - 01/01/1986 a 01/01/1989, Luiza Erundina (Partido dos Trabalhadores) - 01/01/1989 a 01/01/1993, Paulo Maluf (Partido Democrático Social/Partido Progressista Renovador)-01/01/1993 a 01/01/1997, Celso Pitta (Partido Trabalhista Brasileiro) - 01/01/1997 a 01/01/2001, Marta Suplicy (Partido dos Trabalhadores) - 01/01/2001 a 01/01/2005, José Serra (Partido da Social Democracia Brasileira)01/01/2005 a 31/03/2006, Gilberto Kassab (Democratas) - 31/03/2006 a 01/01/2009.

Para entender o contexto atual de formação dos educadores da rede municipal de ensino de São Paulo, fez-se necessário retroceder às políticas públicas de educação de algumas administrações, porque acreditamos que a educação de hoje também resulta de políticas de educação anteriores.

Nesse artigo, procuramos resgatar as alternâncias de políticas públicas na educação desde a gestão de Mário Covas diante da Prefeitura da cidade de São Paulo.

O contexto histórico de lutas e conquistas em torno da educação pública reflete não apenas o trabalho das administrações, mas também o importante papel dos movimentos e as lutas empreendidas pela sociedade civil em torno das demandas e reivindicações ocorridas no espaço urbano da cidade de São Paulo.

Na seção seguinte do artigo, ressalta-se o importante papel dos movimentos sociais para as conquistas da educação pública. Nessa época, as lutas sociais eram em defesa da garantia de direitos e desenvolvimento social e educacional, bem como pelo direito à participação em sociedade que vislumbrava o fim do regime militar.

Na sequência, realiza-se um relato sucinto sobre a criação das escolas da rede municipal de ensino de São Paulo, que se iniciou na primeira metade do século XX e servia apenas à educação infantil. Observa-se, de acordo com os estudos de Sposito (1992), que era atribuição do Poder Estadual a criação e preservação de escolas primárias.

O período de 1983 a 2007 é o tema da última subdivisão, na qual o artigo discorre sobre as políticas públicas para a educação municipal da cidade de São Paulo, evidenciando-se as principais medidas realizadas pelo poder público, até chegar à criação de orientações curriculares e proposições de expectativas de aprendizagem para toda a rede municipal de educação. 


\section{REVISÃO BIBLIOGRÁFICA}

De algum modo, uma pesquisa narra uma trajetória por caminhos muitas vezes já visitados. Na revisita a esses lugares, ocasionalmente, somos levados a olhá-los de forma diferente devido a novas experiências e novos aprofundamentos adquiridos nas vias do conhecimento.

Ao idealizar um sobrevoo histórico pelas administrações do município de São Paulo, foi feita uma investigação bibliográfica apoiada em teses, dissertações, publicações científicas etc. Recorreuse a Gohn (1992, 1995, 2010), Cunha (1991), entre outros, para a fundamentação teórica da descrição do papel dos movimentos sociais para as diversas conquistas arregimentadas pela escola pública.

Os referenciais teóricos que embasaram os relatos dos primeiros anos das escolas que deram origem à rede municipal foram: Fischmann (1988)e Sposito (1992).

Em seguida, outras bibliografias contribuíram com as bases da pesquisa, como Pires (2008) ao estudar os movimentos curriculares da Matemática na rede municipal, principalmente nas gestões a partir de Luiza Erundina. O processo de elaboração deste sobrevoo utilizou-se de portarias e legislações, que deram legitimidade para as tomadas de decisões às implementações feitas nas escolas da rede do município de São Paulo.

\section{METODOLOGIA}

A pesquisa de doutorado da qual essa investigação faz parte é de caráter qualitativo. De acordo com Minayo (1994), é de caráter essencialmente qualitativo uma vez que a realidade social apresenta-se muito mais valiosa do que as teorizações e os estudos empreendidos sobre ela.

Muitos estudos da educação assentados na área das Ciências Humanas seguem a vertente qualitativa de pesquisa. A opção por esse enfoque surge devido à coleta de dados ser realizada na fonte direta: o seu ambiente natural(Qual é o ambiente?). Por outro lado, essa modalidade de pesquisa interage com a realidade estudada nessa investigação. De acordo com Garnica (2001, p. 42), nas pesquisas de abordagem qualitativa, o termo pesquisa recebe outra significação e passa a ser percebido "como uma trajetória circular em torno do que se deseja compreender", não se preocupando unicamente com princípios, leis e generalizações, mas também com a qualidade, de modo a direcionar um olhar atento aos elementos relevantes para o observador-investigador.

Este artigo se estrutura a partir de uma pesquisa bibliográfica e tem o papel de situar o leitor na trajetória política da rede municipal de São Paulo. Assim, optou-se por uma investigação bibliográfica e documental. Ambas as pesquisas se orientam por materiais já escritos. Esta forma de análise "veicula interesses e visões de mundo historicamente construídas e se submete e resiste aos limites dados pelos esquemas de dominação vigentes" (MINAYO, 1994, p. 21).

Desse modo, busca-se apresentar os caminhos do pensamento percorridos para compreensão da realidade em determinado contexto histórico. 


\section{MOVIMENTOS SOCIAIS}

Entre as conquistas na área da educação, bem como o enfrentamento de obstáculos existentes em relação ao acesso e à permanência das pessoas na escola, os movimentos sociais se organizaram em torno da reversão da realidade social. No final da década de 1970 e parte dos anos 1980, os movimentos populares reivindicavam melhorias urbanas articulados com pastorais e grupos políticos de oposição ao regime militar etc.

De acordo com Cunha (1991), os movimentos sociais representavam ações reivindicativas de segmentos de populações - principalmente urbanas - por melhor distribuição de renda, serviço público, saúde, educação etc., buscando melhor qualidade de vida.

Mobilizações populares de trabalhadores sem teto, sem-terra, lutas por empregos, educação pública etc., por uma vida com um mínimo de dignidade humana, caracterizam os movimentos sociais. É nesse panorama que emergem, nascem e se articulam movimentos em torno de necessidades comuns na busca de dias melhores.

Retomar o contexto educacional da cidade de São Paulo, desde os anos 80, sem considerar o papel dos movimentos sociais implica no desconhecimento da participação popular, promotora de mudanças no Brasil.

Maria da Glória Gohn¹, pesquisadora atuante principalmente nos seguintes temas: movimentos sociais, participação social, educação não formal, associativismo e também cidadania, em entrevista, afirma que atualmente os movimentos sociais diferenciam-se dos ocorridos no final dos anos 70 e parte dos anos 80 . Naquela época os movimentos lutavam para ter "direito a ter direitos". Eram movimentos populares reivindicatórios de melhorias urbanas que se articulavam com pastorais e grupos políticos de oposição ao regime militar etc. Hoje os movimentos que antes olhavam para o outro - até para formarem sua identidade- estão autocentrados.

O documento "Subsídios para Diretrizes Curriculares Nacionais Específicas da Educação Básica", expressa o fato de a proteção dos direitos sociais, frente às desigualdades brasileiras requererem não apenas "a presença do estado, como também o controle da sociedade civil, para que as políticas públicas sejam delineadas e implementadas e para que se efetive seu cumprimento" (BRASIL, 2009).

O regime militar no Brasil desencadeou quase duas décadas de enfrentamento de grandes dificuldades para atuação de sindicatos e organizações partidárias. Nessa época, a nação passava por tempos turbulentos no prenúncio de grandes mudanças. Gohn (1995) destaca o período de 1975 a 1982 como um tempo promissor para os movimentos sociais. Foi um tempo de resistência ao regime militar. A crise do petróleo, a lenta retomada da inflação e o desequilíbrio da economia contribuíram para o descrédito do governo militar.

Os movimentos sociais urbanos representavam uma consciência de classe voltada para a construção de uma sociedade igualitária (CUNHA, 1991). Indiferente às necessidades mais elementares para a sobrevivência da população, o Estado com suas políticas antidemocráticas e por sua omissão foi o grande mobilizador dos movimentos sociais.

\footnotetext{
${ }^{1}$ Mestre em Sociologia e doutora em Ciência Política pela Universidade de São Paulo. Pós-doutorado pela New SchoolUniversity, Nova York.
} 
Na década de 1980, o país testemunhou um cenário de lutas e experiências político-sociais. Podemos destacar a luta pelas eleições diretas ${ }^{2}$ em 1984 (GOHN, 1995). O movimento cresceu vertiginosamente amparado na esperança de que a mudança política do regime era fundamental para solução dos problemas.

As lutas em torno da Constituinte de 1988, do Estatuto da Criança e do Adolescente de 1990 e da Lei de Diretrizes e Bases da Educação Nacional de 1996, e as discussões voltadas à atuação do MEC nos anos 90 configuram parte de uma história coletiva de intelectuais, militantes e movimentos sociais.

Em suas pesquisas, Gohn (1995) ressalta a fecundidade dos anos 1980, por ter sido uma década altamente positiva tanto no que diz respeito à política como à cultura. 0 processo de redemocratização andava "a todo vapor", a emergência de novos conceitos mostrando "um deslocamento de estudos centrados na classe operária e suas formas organizativas, como sindicato, comissão de fábrica, centrais sindicais etc., para outros segmentos sociais e outras formas de organização" (PALUDO,2004, p.3).

As importantes mudanças sociais ocorridas nos últimos vinte anos do século XX não foram por acaso e nem iniciativa de governos isolados. Do fim do militarismo ao processo de redemocratização do país, a sociedade pressionou os governantes na reivindicação de mudanças e acesso aos bens construídos pela sociedade. Destacamos como fundamental os movimentos sociais por escola pública que emergiram do descaso e da indiferença dos governantes pelos direitos dos habitantes do país.

Dos novos ventos soprados nos anos de 1980, surgem novos conceitos:

Os moradores dos bairros populares emergem, assim como protagonistas importantes dessa luta pelo acesso; as associações de vizinhos, conhecidas em São Paulo como Sociedades Amigos de Bairros - SABs constituem-se em interlocutores frente a políticos e autoridades, encaminhando demandas diversas, entre as quais está presente a escola (CAMPOS, 1991, p.58).

A educação escolar, nos anos de 1980, viveu profundas contradições. Enquanto setores da sociedade civil se organizaram em torno das demandas de verbas públicas para a educação, ensino gratuito, novas estruturas da carreira docente, novos modelos de escola, entre outros, "a sociedade brasileira assistiu à deterioração progressiva da instituição que já não estava bem: a escola pública em todos os seus níveis" (GOHN, 1992, p.72).

Em 1988, o "Movimento em defesa da escola pública" foi lançado nacionalmente. Esse movimento representou a retomada de movimentos ocorridos anteriormente nos anos 30 pelos Pioneiros da Educação, por exemplo. Em meio às diversas iniciativas dos movimentos sociais organizados na educação, foi criado o Fórum Nacional em Defesa da Escola Pública (FNDEP). Este fórum congregou diversas entidades implicadas com a educação em defesa de sua publicização,

${ }^{2} \mathrm{O}$ Movimento Diretas-Já pode ser considerado um dos maiores movimentos do século XX. Milhares de pessoas se mobilizaram e compareceram em comícios, realizaram passeatas organizadas por comissões suprapartidárias com o objetivo de restabelecer a democracia no país por meio de eleições diretas para a Presidência da República. 
buscando garantir um espaço de dignidade no texto constitucional. Assim, foi garantida na Constituição a educação como direito de todos e dever do Estado.

Foi extraordinária a relevância do FNDEP em sua participação no processo de elaboração da Constituição de 1988:

Ele se constitui numa novidade histórica no processo de agregação das demandas sociais da sociedade brasileira na área da Educação. Embora ele não seja novo em termos de periodização temporal, pois já existiam outros movimentos de defesa da escola pública na história do Brasil, ele representa uma novidade pela forma como se agregou e encaminhou as demandas educacionais (GOHN, 1992, p. 95).

Gohn (2010) declara que os movimentos sociais hoje atuam de maneira diferente. No final da década de 70 e parte dos anos 80, não eram voltados para si próprios, apesar de não terem ainda circulação de espaços globais como hoje, "olhavam para o outro", de modo a formar uma identidade própria, como um efeito espelho. Para fundamentar sua afirmação, a autora refere-se a Lacan que diria: "miravam-se no outro".

O século XXI mudou a feição dos movimentos sociais. De um lado, houve maior reconhecimento das identidades culturais reivindicadas pelos movimentos, por outro lado, há um maior controle social. As políticas públicas passaram a ser o eixo estruturante das ações coletivas organizadas de formas variadas (GOHN, 2010).

Gohn (2010) assevera que atualmente os movimentos sociais adquirem outra feição. Para a autora, os movimentos sociais obtiveram maiores condições de organização, porém grande parte de sua autonomia se perdeu e, por conseguinte, sua força política. Alguns desses grupos transformaram-se em ONGs, outros resistiram eventualmente organizando eventos de efeitos midiáticos sem repercussão importante em suas causas.

Hoje, novos meios são utilizados para divulgar os movimentos sociais referentes à educação. Nessa mesma perspectiva, Nascimento (2004) constata que as universidades estabelecem relações com os fenômenos sociais por meio das pesquisas realizadas. Desse modo, rompem a distância da academia com as necessidades da sociedade. Por meio de congressos, seminários, encontros nacionais e regionais, entre as universidades, estabelecem diálogo não apenas com os responsáveis pelas políticas educacionais, como também com os profissionais da educação.

Os movimentos sociais influenciaram as políticas educacionais ao reivindicarem de maneira intensa à instância federal, estadual e municipal o direito de escola pública, gratuita e de qualidade.

\section{A REDE MUNICIPAL DE ENSINO DE SÃO PAULO}

Ao discorrer a respeito do contexto, sabe-se que o estudo da realidade educativa deve, sempre que possível, partir de um referencial cronológico que nos ajude a compreender as transformações processuais evolutivas - nesse caso - no campo educativo.

Assim, apresenta-se uma breve revisita às administrações anteriores do município de São Paulo, com o objetivo de descrever a trajetória do envolvimento administrativo com a educação básica dessa cidade. 
Até a primeira metade do século $X X$, período em que surgiu a rede municipal de ensino de São Paulo, não havia nada de muito relevante em relação a esse sistema de ensino.

No que se refere à preocupação com os assuntos educacionais, o Município de São Paulo nada apresentava de significativo até a década de 1930. A exceção de um único Parque Infantil ${ }^{3}$ - o "Pedro II" - as escolas instaladas em São Paulo eram mantidas ou pelo Poder Público ou pela Iniciativa Privada (FISCHMANN, 1988, p. 144).

No orçamento do município de São Paulo, nesse espaço de tempo, não constam registros de verbas destinadas à educação pública, salvo alguns reduzidos recursos para a manutenção do Teatro Municipal, da Biblioteca Pública e alguns auxílios e subvenções às escolas particulares mantidas por entidades beneficentes. Tais recursos não excediam a $2 \%$ da receita geral do município 4 .

O início da participação efetiva da Prefeitura de São Paulo na área educacional se deu, a partir de 1935, com o Ato Municipal no767, pelo qual foi criado o Serviço Municipal de Jogos e Recreio, subordinado ao Gabinete do Prefeito. Esse órgão organizava e instalava Parques Infantis. Responsabilizava-se pelas instalações, aparelhamento e o desenvolvimento da prática e diversões.

Restrita à Educação Infantil, a rede municipal foi expandindo-se pelas diversas regiões da cidade. Já em meados da década de 40, a população urbana do Estado de São Paulo dispunha de oportunidades de escolarização em grau primário. A partir dessa década, estado e município firmam um acordo para eliminar a carência de vagas no município de São Paulo.

Na década de 40, novas medidas surgem no âmbito do Poder Público, tendo em vista uma resposta mais eficaz às necessidades crescentes de expansão do ensino primário da cidade. Nesse período, Estado e Prefeitura passam a agir em conjunto visando suprir as deficiências na oferta de matrículas da escola elementar no município da capital (SPOSITO, 1992, p.35).

A contribuição da Prefeitura do Município de São Paulo com a criação, manutenção e oferta de serviços educacionais à população da cidade era ínfima "cabendo ao Poder Estadual a iniciativa de criação e manutenção dos estabelecimentos de Ensino Primário" (SPOSITO, 1992, p.35).

Dois convênios foram firmados entre Estado e Prefeitura para o estabelecimento de ações conjuntas em torno de serviços educacionais, um em 1943 e outro em 1949. O município construiria prédios para abrigar grupos escolares, enquanto que ao Estado caberia a criação e instalação de classes e escolas, bem como a nomeação de professores. Quando terminou o prazo do segundo convênio, não houve acerto entre as partes, fato que culminou com a criação por parte da Prefeitura do seu próprio sistema de ensino.

A Prefeitura inicia atividade independente na oferta da escolaridade elementar à população do município. Diante das divergências que se estabeleceram em relação à entrega de novas unidades, já que o terceiro Convênio não fora ratificado, o Chefe do Executivo Municipal cria em 5 de fevereiro de 1956 o Grupo Escolar Municipal e principia estudos que se

\footnotetext{
${ }^{3}$ O Parque Infantil era destinado às crianças de 3 a 12 anos, filhas de trabalhadores da região, criado em 1936 por Mário de Andrade, à época, diretor do Departamento de Cultura da Prefeitura do Município de São Paulo. O Parque Infantil corresponde hoje à Educação Infantil.

${ }^{4}$ Informações extraídas do Livro de Leis e Resoluções da Câmara Municipal do Estado de São Paulo, pertencente ao acervo da Secretaria Municipal de Educação.
} 
consubstanciam na regulamentação do ensino municipal por meio do Decreto-Lei de 2 de agosto de 1956 (SPOSITO, 1992, p.39).

Na década de 50, houve um considerável crescimento dessa rede municipal e, entre 1955 e 1956, foram criadas 34 novas escolas. Paralela a essa expansão, os órgãos e as pastas responsáveis pela educação foram reestruturados.

No ano de 1956, houve a oficialização do sistema público de educação na cidade de São Paulo. Embora a educação na cidade já houvesse começado antes dessa data, 1956 deve ser visto como um marco, pois oficializou a criação de um sistema público de educação na cidade. Desde então, o crescimento da rede municipal de ensino avança rapidamente, perfazendo mais de cinquenta mil matrículas, no final dos anos 50.

A rede municipal de ensino se expandiu e adquiriu sua própria identidade com características diversas da rede estadual de São Paulo. Inicialmente, as escolas do município e do estado foram distribuídas nos bairros da cidade de modo desordenado, que com o tempo foi corrigido.

Aqui, então, apresentamos algumas políticas de formação continuada realizadas nas administrações desde Mario Covas até Gilberto Kassab. Os mediadores de currículo idealizados e implementados na gestão de Gilberto Kassab são objetos da pesquisa do presente artigo que tem como foco as "Orientações Curriculares e Proposições de Expectativas de Aprendizagem para o ciclo II de Matemática".

\section{PERÍODO DE 1983 A 2007}

Com um histórico de tradição de lutas pela democracia no Brasil, Mario Covas é nomeado prefeito da cidade de São Paulo, em 1983, pelo então governador Franco Montoro. Em direção oposta às políticas anteriores, que os prefeitos vinham gerindo na educação, iniciava-se a política educacional do governo Mario Covas. Ele e seu partido, então PMDB, que eram oposição ao Regime Militar, depois de 16 anos protagonizavam o início do processo de abertura política (CISESKI, 1997).

Assim, quando assumiu a Secretaria Municipal de Educação de São Paulo em 1983, Guiomar Namo de Mello possuía as condições necessárias para isso.

Na década de 1980, estava em pauta a retomada da relevância dos conteúdos. A revisão curricular tinha em vista aproximar os conteúdos da realidade dos alunos além de atualizá-los. Essa posição era defendida pelo grupo fundamentado em Demerval Savianni.

A proposta de educação levada a (SME) pelo grupo dirigente fundamentava-se em Gramci, que era traduzida pela concepção histórico-crítica da educação. Uma das preocupações do grupo que elaborou a proposta era a retomada da especificidade da escola: ensinar com competência e comprometimento com o aluno.

Segundo Cunha (1991), ao Guiomar Namo de Mello relatar alguns aspectos das reflexões realizadas por ela e sua equipe após dois anos de administração revelou que de todas as lições que a teoria ensina só a vida faz aprender. Três questões representaram um grande aprendizado para equipe da SME: a primeira é que toda e qualquer democratização e melhoria da escola é tarefa coletiva, senão é ineficaz. A segunda é que toda e qualquer democratização e melhoria da escola é 
um processo de natureza cotidiana. A única mudança eficaz é aquela que tem como referência inicial a prática concreta, cotidiana e rotineira.

Porém, não houve continuidade ideológica frente à prefeitura de São Paulo e a educação em assume outros rumos.

A alternância de concepções políticas no poder foi uma marca nas administrações do município de São Paulo. Nos últimos trinta anos, dois momentos se destacaram por mudanças abruptas que culminaram em atitudes radicais por parte da administração.

O primeiro momento contemplou a ruptura do trabalho desenvolvido na gestão de Guiomar Namo de Mello como Secretária de Educação.

Cunha (1991) assevera que se a reflexão do grupo de Guiomar Namo de Mello fosse feita um ano depois da mudança de administração seria acrescentada mais uma lição: a de que a continuidade é imprescindível para o êxito das políticas educacionais. Jânio Quadros, que sucedeu a Mário Covas, mandou apreender publicações distribuídas às escolas pela administração anterior, com o principal objetivo de confiscar a coleção "Retratos do Brasil", publicada pela Editora Três.

Ao assumir o governo, o prefeito Jânio Quadros iniciou a "reorientação da política educacional pelas providências repressivas" (CUNHA, 1991, p. 223). Foi proibida a afixação de cartazes de "cunho ideológico" nas dependências das escolas e Secretaria Municipal de Educação.

Jânio Quadros revogou o regimento comum das escolas, implantado no governo Mario Covas, e retomou o que estava em vigor no início da década com o objetivo de retirar o poder dos conselhos de escola. Aglutinou as Secretarias de Educação e do Bem-Estar Social e reformulou estruturas, funções e divisões das instâncias burocráticas dessas secretarias.

A educação não era prioridade e privilegiou setores de grandes obras viárias reduzindo os recursos financeiros das obras sociais (CISESK, 1997). Desse modo, podemos afirmar que o processo de democratização retrocedeu na administração de Jânio Quadros.

As medidas autoritárias e repressivas de Jânio Quadros provocaram a reação do magistério da rede municipal. Em 1987 foi deflagrada a maior greve dos educadores do município de São Paulo, que durou19 dias. Reivindicavam melhorias salariais e democratização das relações entre escolas e órgãos superiores. Não havia disposição de dialogar com a entidade representante da categoria, bem como era reprimida qualquer tipo de manifestação contrária à política do governo. Em contrapartida, a administração de Jânio Quadros valorizou o especialista e o diretor de escola.

Nas eleições seguintes, o poder municipal oscilou para outro extremo. Luiza Erundina foi eleita em 15 de novembro de 1988, representando uma proposta democrática popular. A pasta da educação foi assumida por Paulo Freire.

A administração de Paulo Freire seguida dois anos depois por Mario Sergio Cortella estava comprometida com a construção de uma escola pública popular. Silva e Saul (2009) relatam que esse compromisso previa uma educação na perspectiva democrática, por isso era urgente a democratização do país. Caberia edificar uma escola por um lado cientificamente rigorosa e ética, e por outro lado alegre, acolhedora e aberta para a participação popular.

Para a concretização da escola pública popular de boa qualidade, a Secretaria Municipal de Educação desenvolveu projetos na direção de uma educação crítica e transformadora. Podemos 
destacar as seguintes ações: o Movimento para a Reorientação do Currículo (com o Projeto da Interdisciplinaridade), Grupos de Formação (para professores, coordenadores pedagógicos e diretores de escolas), o Projeto Gênese (um programa de ensino de utilização de computadores) e o MOVA (Movimento de Alfabetização de Jovens e de Adultos).

Paulo Maluf, ao assumir a prefeitura em 1993,interrompeu abruptamente o trabalho da gestão anterior. Rompeu com o processo de democratização do ensino implementado na gestão de Luiza Erundina e buscou o fortalecimento da Qualidade Total ${ }^{5}$, que com o tempo abrangeu todas as secretarias do município.

Com ideologia oposta, a administração de Paulo Maluf buscou modos de gerenciar e racionalizar a máquina pública. A proposta educacional da administração fundamentou-se nos princípios da Qualidade Total, modelo importado do molde gerencial utilizado nas empresas.

O modelo pautado na Qualidade Total não encontrou guarida nas escolas da rede municipal de ensino, de modo que essa ideia não foi desenvolvida.

Concomitantemente, em nível nacional, iniciava-se a elaboração dos Parâmetros Curriculares Nacionais (PCNs) para os diferentes níveis e modalidades de ensino. Esse material traz a primeira tentativa de uma matriz curricular nacional. Os conteúdos se dividem em eixos e são apontados os objetivos de cada área do conhecimento. Também, nessa época, o Conselho Nacional de Educação (CNE) apresentou as Diretrizes Curriculares Nacionais. Desse modo, as discussões em torno do currículo intensificaram-se na rede municipal de ensino.

Em 01/01/2001 Marta Suplicy assumiu a Prefeitura de São Paulo. Sua eleição representou os ideais progressistas, opostos ao conservadorismo de direita representado por Paulo Maluf.

A Secretaria Municipal de Educação manteve um diálogo com os educadores durante toda gestão de Marta Suplicy por meio dos cadernos EducAção. Foram anunciadas para todas as modalidades de ensino três linhas de ação: movimento de reorientação curricular; formação permanente e sistemática; repensar a avaliação e o funcionamento da escola.

Além disso, foram produzidos documentos na forma de cadernos pela SME/DOT que marcaram o diálogo entre a Secretaria de Educação e os educadores nas escolas, do início ao fim da gestão de Marta Suplicy como prefeita.

O caderno EducAção 1 introduziu a política educacional da prefeitura com três artigos: o primeiro artigo intitulava-se "Ficar na escola e gostar dela é um direito de todos: a qualidade social da educação"; o segundo artigo, com o tema "Participar da escola é um direito de todos: a democratização da gestão"; e o terceiro artigo, "Ter escola de qualidade é um direito de todos: a democratização do acesso e da permanência". Esses artigos evidenciaram as metas estabelecidas para gestão da educação.

O caderno EducAção 2 discutiu a Formação Permanente dos Professores e o Movimento de Reorientação Curricular. O documento EducAção 3 apresentou a síntese das três diretrizes municipais, do movimento de reorientação curricular e da formação contínua de professores. E o

\footnotetext{
${ }^{5} \mathrm{Na}$ administração de Paulo Maluf, foi adotado como política educacional a filosofia da Qualidade Total na Escola, divulgada no livro de Cosete Ramos: Excelência em educação de qualidade total. Rio de Janeiro: Quality, 1992.
} 
documento EducAção 4 "Cidade Educadora - Educação Inclusiva - Um sonho possível" era constituído de sete textos com o intuito de aprofundar o debate das metas da gestão.

O último caderno dessa série, o EducAção5,trouxe as reflexões dos temas destacados na revista EducAção 4 e no caderno temático n.1, reacendendo o debate de pontos conflituosos no cotidiano escolar a partir de textos reflexivos.

No ano de 2005, na gestão de José Serra se evidenciou, mais uma vez, a alternância de concepções ideológicas partidárias na administração municipal e uma nova proposta para a educação foi posta em prática.

O Diário Oficial da Cidade de São Paulo de 24 de fevereiro de 2005 publicou um suplemento intitulado: "Educação no município de São Paulo: uma proposta para discussão". Nele, o Secretário de Educação apresentou um diagnóstico da rede municipal de educação e apontou como "problemas dramáticos" a falta de vagas para crianças de 0 a 3 anos e a qualidade do Ensino Fundamental, "apesar do empenho dos professores e dos dirigentes de educação que se sucederam nessas últimas décadas".

Evidentemente sua realização dependerá de uma avaliação periódica de todos os alunos e de uma organização de condições que promovam esse reforço absolutamente necessário, que deve ser contínuo, paralelo ao currículo, para todos os alunos com dificuldades de aprendizagem e necessidades especiais de todas as ordens, para que a educação supere as diferenças culturais, sociais e individuais (SÃO PAULO, 2005a, p. 22).

A formação continuada dos professores, segundo o Secretário de Educação, deveria ser implementada pela Diretoria de Orientações Técnicas (DOTs) com o Diretor de escola como articulador principal, o Coordenador Pedagógico responsável pela gestão das ações e a escola como campo de atuação da formação.

Em de 26 de setembro de 2005, o Secretário da Educação, por meio da Portaria no 6.328, instituiu, para o ano de 2006, o Programa "Ler e escrever - prioridade na Escola Municipal", nas Escolas Municipais de Ensino Fundamental (EMEFs) e Escolas Municipais de Ensino Fundamental e Médio (EMEFMs). O programa Ler e Escrever tinha por objetivo desenvolver projetos que possibilitassem "reverter o quadro de fracasso escolar ocasionado pelo analfabetismo e pela alfabetização precária dos alunos do Ensino Fundamental e Médio da Rede Municipal de Ensino" (SÃO PAULO, 2005b).

Depois de um ano e três meses, o vice-prefeito dessa gestão, Gilberto Kassab, assumiu a prefeitura, devido à candidatura do prefeito eleito José Serra ao governo do estado de São Paulo. Na gestão subsequente, Gilberto Kassab se reelegeu e as propostas de um currículo prescrito para toda a rede municipal teve continuidade.

O programa Ler e Escrever foi reorganizado, de acordo com a Portaria 5.403/07 (SÃO PAULO, 2007), atingindo todos os anos do ciclo I e II do Ensino Fundamental e Médio, inclusive as Escolas Municipais de Educação Especial (EMEls).

Nessa administração foram elaboradas e implementadas as Orientações Curriculares e as Expectativas de Aprendizagem de todas as disciplinas do ciclo II. 
Assim, evidenciamos nessa breve apresentação as diferenças de concepções políticopedagógicas, ideológicas e epistemológicas que embasaram a prática nas escolas da rede municipal de São Paulo ao longo de diferentes gestões, com suas propostas e contradições que por vezes provocaram a ruptura da construção de uma escola consistente e democrática.

\section{CONSIDERAÇÕES FINAIS}

Nesse artigo, inicialmente, analisa-se o contexto dos antecedentes políticos com uma retomada da história da rede municipal de São Paulo. São destacadas algumas administrações municipais, desde 1983, devido ao processo de redemocratização com ênfase nas políticas de formação de professores até chegarmos à gestão que promoveu a criação das Orientações Curriculares e proposições de expectativas de aprendizagem.

Procurou-se nesse estudo identificar o percurso dos governantes da cidade de São Paulo desde Mario Covas a Gilberto Kassab com o propósito de contextualizar a educação na rede municipal, uma vez que se considera o seu passado educacional essencial para as tomadas de decisões referentes ao currículo da rede.

As implementações curriculares realizadas nos anos de 1983 a 2007trazem no seu bojo uma trajetória política de alternância de poder no executivo municipal. De um lado havia administradores que valorizavam muito a educação no município, investindo tanto nas escolas como nos profissionais da educação. Por outro lado, a população do município de São Paulo contou com governos que romperam abruptamente com as políticas educacionais anteriores, como foi o caso da administração de Paulo Maluf (1993-1996) em relação às realizações da administração Luiza Erundina (1989 a 1992) que havia desencadeado o Movimento de Reorientação Curricular nas escolas da rede municipal de São Paulo. Outra importante ruptura ocorreu anteriormente na gestão de Jânio Quadro que desconsiderou as implementações democráticas da gestão de Mario Covas, e rompeu as realizações ocorridas nas escolas da rede municipal da cidade de São Paulo. Do recorte temporal destacado nesse artigo de 1983 a 2007,as gestõesde Jânio Quadros e de Paulo Maluf protagonizaram os rompimentos mais radicais com as políticas educacionais anteriores.

Evidencia-se, que a grande alternância de poder e de concepções político-partidárias, impedem a continuidade dos trabalhos realizados nas administrações.

\section{REFERÊNCIAS BIBLIOGRÁFICAS}

1. BRASIL. Subsídios para diretrizes curriculares nacionais específicas da educação básica. Brasília: MEC, 2009.

2. CAMPOS, Maria Malta. As lutas sociais pela educação. Cadernos de Pesquisa, São Paulo: Fundação Carlos Chagas, n.79, nov. 1991.

3. CISESKI, Ângela Antunes. Aceita um conselho? Teoria e prática da gestão participativa na escola pública. São Paulo, 1995. Dissertação de Mestrado- Faculdade de Educação-Universidade de São Paulo, 1995.

4. CUNHA, Luiz Antonio. Educação, Estado e democracia no Brasil. São Paulo: Cortez Niterói, RJ: UFF; Brasília, DF: Flacso, 1991. 
5. FISCHMANN, Roseli. Estrutura administrativa da Secretaria Municipal deEducação da Prefeitura do Município de São Paulo (um estudo de fatores condicionantes).Estudos e Documentos, FEUSP, v.29, 1988.

6. GARNICA, Antonio V. M. Pesquisa qualitativa e Educação (Matemática): de regulações, regulamentos, tempos e depoimentos. Mimesis, Bauru, v. 22, n. 1, p. 35-48, 2001.

7. GOHN, M. G. Movimentos sociais e educação. São Paulo: Cortez, 1992.

8. _ Movimentos e lutas sociais na História do Brasil. São Paulo: Loyola, 1995.

9. Entrevista. Maria da Glória Gohn. 19 abr. 2010.IHU on-line - Revista do Instituto Humanitas Unisinos.

10. MINAYO, Maria Cecíliade Souza. O desafio do conhecimento. São Paulo/Rio de Janeiro: HUCITEC-ABRASCO, 1994.

11. NASCIMENTO. Antonio Dias. Movimentos sociais e educação. In: Caderno de Pesquisa. Universidade do Estado da Bahia/Departamento de Educação/ Programa de Pós-Graduação em Educação e Contemporaneidade - PPGEduC, Salvador, v.2 , n. 2. jun. 2004.

12. PALUDO, Conceição. Movimentos sociais e educação popular: atualidade do legado de Paulo Freire. Cadernos de Pesquisa. São Paulo: Fundação Carlos Chagas, Nascimento, 2004.

13. PIRES, Celia Maria Carolino. Educação Matemática e sua influência no processo de organização e desenvolvimento curricular no Brasil. Bolema, Rio Claro (SP), ano 21, n. 29, p. 13-42, 2008.

14. São Paulo. Diário Oficial do Município: Programa Ler e escrever - Prioridade na Escola Municipal. Portaria no 6328, 27/09/05. São Paulo: 2005a.

15. _. Secretaria Municipal de Educação. Portaria SME n. 6.328, de 26 de setembro de 2005b. Implementa o Programa "Ler e Escrever - Prioridade na Escola Municipal", nas escolas municipais de ensino fundamental - EMEFMs. Disponível em: <http://www3.prefeitura.sp. gov.br/cadlem/secretarias/negocio>. Acesso em: 14 maio 2014.

16. Secretaria Municipal de Educação. Portaria SME n. 5.403, de 16 de novembro de 2007. Reorganiza Programa "Ler e Escrever - Prioridade na Escola Municipal", nas EMEFMs. EMEFMs e EMEEs. Disponível em: <http://portalsme.prefeitura.sp.gov.br/Projetos/super visao/An>. Acesso em: 16 nov. 2014.

17. SAUL, Ana Maria; SILVA, Antonio Fernando Gouvêa da. O legado de Paulo Freire para as políticas de currículo e para a formação de educadores, no Brasil. Revista Brasileira de Estudos Pedagógicos. Brasília, v.90, n.224, p.223-244, jan/abr.2009.

18. SPOSITO, Marília Pontes. O povo vai à escola: a luta popular pela expansão do ensino público em São Paulo. São Paulo: Loyola, 1992. 